\title{
Review of e-portfolio requirements and methodology
}

\author{
Joseph Wan*1, Neil H Metcalfe ${ }^{2}$ \\ ${ }^{1}$ University of Manchester, School of Medicine, Manchester, United Kingdom \\ ${ }^{2}$ Manchester Medical School, Manchester, United Kingdom
}

Received: October 4, 2015

Accepted: December 13, 2015 Online Published: December 21, 2015

DOI: $10.5430 /$ jha.v5n2p29

URL: http://dx.doi.org/10.5430/jha.v5n2p29

\begin{abstract}
Background: Portfolios are used in medical practice as a means of instilling "reflective learning" in doctors and accumulating evidence of the doctor's competence. It is a mandatory requirement by the General Medical Council (GMC), as a form of public accountability, for licensed clinicians to maintain an e-portfolio of daily clinical practice, which is subjected to annual appraisals and ultimately influences their ability to renew their license to practise in the UK. This article reviews the reflective learning process for which the e-portfolio is intended to instil in doctors and the level of evidence required to demonstrate competency and continuing professional development.

Methods: A literature review was conducted on Medline and Google Scholar for any available guidance on writing e-portfolio entries and guidelines from the GMC, Royal Colleges and various training boards were reviewed to determine the type of evidence required to be demonstrated.

Results: Fifteen articles had met the inclusion criteria on guiding e-portfolio writing. Guidelines reviewed constantly echoed the theme of "reflecting doctors" and "linking evidence to curriculum outcomes". This article has also proposed a "Do, Reflect, Plan, Act" framework in writing portfolio entries.

Conclusions: Creating and maintaining an e-portfolio throughout a lifelong career is no mean feat. We have reviewed the key components that clinicians ought to demonstrate in their e-portfolios, and introduced the "Do, Reflect, Plan, Act" framework, to enhance understanding of the e-portfolio as a learning tool to improve medical practice.
\end{abstract}

Key Words: E-portfolio, Re-validation, Reflection, Continuing professional development, Competency

\section{BACKGROUND}

A portfolio (a record of evidence showcasing the doctor's experience, achievements and competencies) is an essential tool in the career of any medical professional. ${ }^{[1,2]}$ These records are reviewed at various milestones of a doctor's training, to ensure that he or she has attained the relevant experiences and competencies required to gain specialist recognition or to progress to the next stage of training.

In the United Kingdom, existing physicians in practice are also required to maintain portfolios by the General Medical
Council (GMC). ${ }^{[3,4]}$ The GMC introduced licences to practise in 2009, separate from the GMC register, requiring a revalidation process every 5 years in order for the clinician to continue practising medicine in the UK. ${ }^{[5,6]}$ This acts as a form of public accountability, ${ }^{[7]}$ ensuring a competent healthcare workforce as highlighted in the Department of Health's "Reference Guide for Postgraduate Specialty Training: Gold Guide". ${ }^{[8]}$ A major part of the revalidation process includes an annual appraisal of the clinician's e-portfolio, showcasing their work experiences throughout the year, to demonstrate that they are well-qualified to carry out safe clinical practice.

\footnotetext{
*Correspondence: Joseph Wan; Email: jywanjoseph@gmail.com; Address: University of Manchester, School of Medicine, Stopford Building, Oxford Road, M13 9PT, Manchester, United Kingdom.
} 
More recently, these portfolios have moved to electronic platforms (dubbed e-portfolios) where the practitioner organises and maintains an online database of evidence. ${ }^{[9]}$ Various medical schools have also developed their own portfolio databases for students to upload their work, log reflections and feedback ${ }^{[7,10,11]}$ as a means of an early introduction to what will be a life-long practice of reflective learning throughout the students' careers in accordance with the GMC's guidance Tomorrow's Doctors (2009). ${ }^{[12]}$

As much as the e-portfolio is important, various studies have shown that it is met with mixed responses and perceptions from junior doctors and medical students. ${ }^{[1,13]}$ While most understood the importance of reflecting on practice, many felt that it is a tiring administrative exercise on top of a busy schedule. ${ }^{[1]}$ Many also felt that there is inadequate guidance in the e-portfolio interface they are required to use. This problem has also been highlighted in the British Medical Association's (BMA) Medical Students Conference 2013, which called for a unified e-portfolio system to be used across different institutions. ${ }^{[14]}$

This article reviews the reflective learning process for which the e-portfolio is intended to instil in doctors and the level of evidence required to demonstrate competency and continuing professional development as part of medical training curriculum and revalidation.

\section{LITERATURE REVIEW}

A literature search was carried out to further understand the role an e-portfolio plays in modern day medical profession, and the level of evidence required in it to demonstrate competence in doctors. A search was done electronically on Medline and Google Scholar using free text search terms "medical" and "e-portfolio", along with advanced search filters to display studies published since 2009.

\section{Inclusion criteria}

Review papers and research publications were considered eligible if they demonstrated:

(1) The purpose of e-portfolio in the medical profession;

(2) How clinicians and trainees perceive the portfolio;

(3) What aspects of medical education is considered important for review;

(4) How to write them.

Table 1. Breakdown of literature search from Medline and Google Scholar databases

\begin{tabular}{llll}
\hline & Medline & Google Scholar & Total (minus overlapping articles) \\
\hline Total number of citations returned & 42 & 4140 & \\
Number of full articles retrieved & 11 & 22 & 30 \\
Number of articles included in criteria & 3 & 13 & 15 \\
\hline
\end{tabular}

Four thousand, one hundred and eighty-two citations were returned, of which 30 are considered relevant after reviewing the titles and abstracts. Full articles were retrieved for further assessment, and of which 15 had met the inclusion criteria.

In the UK, e-portfolios are annually reviewed as part of GMC requirements for revalidation and training progression, in a process known as Annual Review of Competence Progression (ARCP). ${ }^{[15-17]}$

GMC guidelines were also consulted as part of this review, Tomorrow's Doctors, ${ }^{[10]}$ Good Medical Practice ${ }^{[3]}$ and Good Manufacturing Practice (GMP) Framework for appraisal and revalidation ${ }^{[4]}$ has laid out clear objectives which medical students or practitioners being appraised for revalidation should demonstrate in their e-portfolios.

Several Royal Colleges and institutions overseeing advanced clinical training have also published various documents on the ARCP process and criteria on aspects of training. Foundation Programme ${ }^{[16]}$ and Specialty Training curriculums ${ }^{[18-21]}$ were also reviewed as a guide to the types of evidence required in the e-portfolios for training progression.

\section{Discussion}

Several studies ${ }^{[7,9,11,22,23]}$ have advocated that e-portfolios are particularly useful as a record of experience and promotes independent reflective learning, to think back about those experiences. The record can be in the form of a logbook or a diary of day to day work experiences, ${ }^{[5,6]}$ which is especially important in the highly skills-dependent healthcare profession where the learning takes place in a working clinical environment as opposed to a classroom teaching basis. ${ }^{[2]}$

Several studies ${ }^{[9,11,13]}$ have also found that trainees prefer an electronic interface of managing a portfolio, stating it to be better suited to the active way of work in a clinical environment. In the UK, electronic portfolio interface is now readily available to clinicians and trainee doctors by most institutes and Royal Colleges, ${ }^{[5,6]}$ and even generic ones are freely available by various organisation that cater to the medical 
profession as a whole, for example the BMA.

The e-portfolio also serves as a comprehensive evidence base for showcasing the work and experience a clinician has accumulated during the time of work. These will be appraised annually as part of the GMC's obligation to evaluate if the clinician is well-qualified to continue safe clinical practice $^{[3,4]}$ or to progress to a higher level of training within the curriculum. ${ }^{[16]}$ These appraisals are also a good platform for the clinician to collate feedback on the service he/she is providing, and to work out on any improvements. ${ }^{[5,6]}$

However, given the diversity of clinical work, there can be limitations to the appraisal process. The guideline published by the Royal College of Anaesthetist had raised the possibility of the appraiser being from a vastly different specialty of medicine from the appraisee, hence unable to fully determine if appraisee has maintained the key skills necessary to fulfil his or her clinical commitments. As such, it might be prudent for a clinician to be appraised by a peer of the same specialty. ${ }^{[24]}$

\subsection{Key components in medical e-portfolios}

The GMC has published various guidelines, such as Tomorrow's Doctors, ${ }^{[12]}$ Good Medical Practice ${ }^{[3]}$ and GMP Framework for appraisal and revalidation, ${ }^{[4]}$ which lays out a clear framework of objectives which medical students or clinicians being appraised should demonstrate in their e-portfolios. More importantly, they ought to use this framework as a basis for continued reflection on their daily practice (see Figure 1).

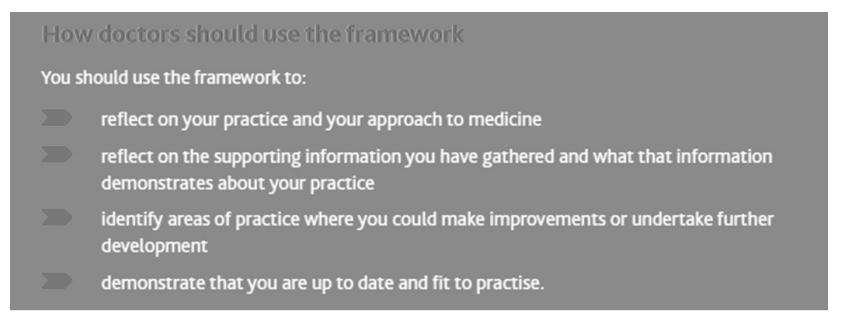

Figure 1. Excerpt from GMP framework for appraisal and revalidation (2013) on attributes to demonstrate during appraisal $^{[4]}$

The revalidation for doctors undergoing postgraduate training (i.e. a Foundation doctor, surgical or GP registrar) is largely governed by their training curriculum in the yearly ARCP process. ${ }^{[16,18-21]}$ Their e-portfolios, which includes their training logbook, reports from their educational supervisors and worked-based clinical supervision, are reviewed by a panel of assessors, usually made up of College Education or Training Programme Fellows. These are used as a form of evaluation to determine whether a trainee has achieved

Published by Sciedu Press a level of competence expected of his/her level of training, which is then used to build on the objectives to be met for the following year's ARCP meeting. ${ }^{[18-21]}$

Recommendation for trainees' revalidation will be based on the ARCP, including an exit report confirming that the trainee has not been involved in any serious untoward incident investigation, or named in a complaint. Continuing professional development (CPD) credits for revalidation will not be required at this stage as their training is, by nature, developmental. ${ }^{[5,6]}$

Reflecting the diversity of clinical practice, several Royal Colleges ${ }^{[5,6,24,25]}$ and Training Boards ${ }^{[18-21]}$ have also published guidelines in line with those published by the GMC, outlining more specific details on the types of evidence that clinicians ought to detail in their e-portfolios. The key areas are highlighted below.

\subsection{Personal details}

This is somewhat like a curriculum vitae, ${ }^{[26]}$ which should describe a clinician's current place of work and designation, scope of work, prior experience, details of education and qualifications, as well as GMC registration. Another stated requirement for appraisals is signed self-declarations for probity, criminal discharge and the clinician's own health. ${ }^{[5,6]}$

\subsection{Daily clinical activity}

The type of work undertaken can vary across specialties. ${ }^{[24,25]}$ A logbook of cases and procedures performed can be used to demonstrate maintained competency in a certain skill or clinical knowledge. This can also include feedback on practice by colleagues and patients or sign-offs from an appropriate consultant/expert/colleague. Occasionally, significant events, such as poor patient outcomes or near-misses, do occur and ought to be recorded separately to be reflected upon and to develop an action plan. ${ }^{[5,6]}$

Work not involving clinical practice might not require a renewal of license to practise, ${ }^{[4]}$ but a portfolio ought to be maintained, detailing any patient contact or academic and research activities undertaken, ${ }^{[5,6]}$ as well as feedback on teaching that was delivered. ${ }^{[22]}$

\subsection{Quality improvement activity}

Under the guidelines laid out by the GMC, ${ }^{[3,4]}$ a competent clinician ought to be familiar with the audit process and involved in quality improvement and to showcase that, at least one audit should be performed every 5-year revalidation cycle and well documented in the portfolio. This can be in form of any data collection, presentations or interventions carried out to improve service. ${ }^{[5,6]}$ 


\subsection{CPD}

It is essential for clinicians to stay up to date with the latest research and techniques. ${ }^{[27]}$ A learning credits system known as CPD was introduced for learning activities outside of undergraduate education or postgraduate training for clinicians to help develop and maintain skills across practice. All new and refresher education or development activities ought to be recorded and reflected upon in the e-portfolio for each appraisal meeting. Normally, an achievement of at least 50 credits per year is expected and at least 250 credits over a 5 year revalidation cycle. ${ }^{[5,6,25]}$

3.6 Learning through reflections: Do, Reflect, Plan, Act "Reflecting doctors" is an essential value constantly echoed throughout various guidelines published by the $\mathrm{GMC}^{[3,4,8]}$ and the Department of Health's Gold Guide ${ }^{[8]}$ for medical professionals at various stages of training. Doctors are required to keep a "learning log", ${ }^{[8,16,20]}$ in which they review on day-to-day practice and this log is discussed in appraisals and educational supervisor meetings.

Benjamin et al. ${ }^{[28]}$ described the clinical audit cycle as "cyclical or spiral systematic process, with the ultimate aim of improving care", which shares similar processes and goals as the reflective learning log. A simplified version of "Do, Reflect, Plan Act" can be used to describe reflective learning as a cyclical and continuous process, similar to a clinical audit (see Figure 2).

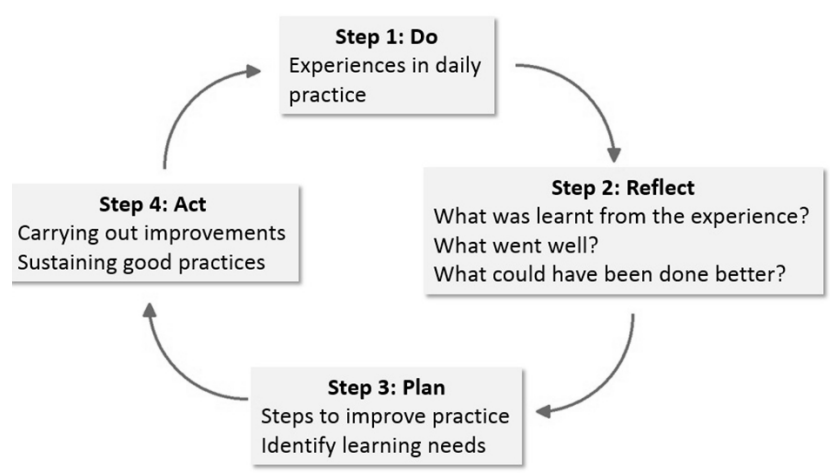

Figure 2. "Do, Reflect, Plan, Act" cycle adapted and simplified from the Clinical Audit Cycle, used in reflective learning and continuous process of self-development and improvement. ${ }^{[28]}$

\section{Step 1: Do}

This should be a record of daily events in practice, which can be on any form work experience ranging from clinical practice (patients seen, working relations with colleagues, carrying out a procedure $e t c$.) to any aspects of medical education (meeting with supervisor, teaching others, research work etc.). ${ }^{[12]}$ Ideally, any significant events with learning opportunities ought to be logged, ${ }^{[16]}$ but it will be especially important to log events that correspond to the learning outcomes in the curriculum (explained further in "Linking Evidence" heading).

\section{Step 2: Reflect}

The experience or event has already taken place and this is the stage during which it is evaluated by a third person, who would evaluate the practice as poor or good practice (according to current guidelines) and what improvements should be ${ }^{[7,10]}$ Feedback from others, for example patients, supervisors, students, should also be taken into account. ${ }^{[10]}$ Focus should be placed heavily on the learning points of the experience, identifying own learning needs and how it will change future practice.

\section{Step 3: Plan}

Once the learning requirements or areas of improvement have been identified, it is time to draw up a plan to implement them. ${ }^{[10-13]}$ It can be as simple as "read up NICE guidelines in managing unstable angina" or something that requires more planning such as "arrange a session in the GUM clinic and explore ethical considerations in sexual health".

\section{Step 4: Act}

Finally, it is time to act on the plan and to provide evidence of having done so, by logging the date of completion or having it signed off by a supervisor for it. ${ }^{[17,18]}$ If any learning experience or improvement ideas are picked up during the course of carrying out the action plan, this can be logged in as new entry, and one repeats the cycle of reflecting and acting on it.

This is a simple and organised method of demonstrating insight and analysis of daily practice, similar to carrying out a self-audit. This framework can be applied in the format of a logbook (see Table 2), exhibiting reflection and followthrough to improve practice.

\subsection{Linking evidence}

After accumulating a year's worth of experience and reflections, it is vital to link these entries to the competencies laid out in the programme curriculum in preparation for an educational supervisor meeting and ARCP review. ${ }^{[5,14,17]}$ This is a means of showing that the programme's learning objectives have been achieved, or that good practices have been maintained. ${ }^{[29]}$

Each outcome will need at least one log, thus it will be worthwhile reading the relevant programme curriculum upon start of training, ${ }^{[30]}$ so as to identify outcomes that are "harder 
to come by". For example, to fulfil the requirement of "An absolute minimum 10 Mastoid Operations as principle surgeon" as laid out in the curriculum, ${ }^{[30]}$ an ENT surgical trainee might need to make necessary prior arrangements to attain the relevant experiences. Some Specialty training programmes also require minimum attachment periods to different departments, thus it is necessary to log the dates when placements are started and completed. ${ }^{[31]}$

Table 2. Worked example of a learning log demonstrating the "Do, Reflect, Plan, Act" framework (Names and patient data have been anonymised to preserve confidentiality)

\begin{tabular}{|c|c|c|c|c|c|}
\hline \multirow{2}{*}{ Date } & \multirow{2}{*}{$\begin{array}{l}\text { Do } \\
\text { Summary }\end{array}$} & \multicolumn{2}{|c|}{ Reflect } & \multirow{2}{*}{$\begin{array}{l}\text { Plan } \\
\text { Learning Needs }\end{array}$} & \multirow{2}{*}{$\begin{array}{l}\text { Act } \\
\text { Achieved? }\end{array}$} \\
\hline & & Reflection & Feedback given & & \\
\hline $\begin{array}{l}29 \text { Jan } \\
2015\end{array}$ & $\begin{array}{l}\text { - PC: } 69 \text {-year-old lady presented to } \\
\text { A\&E with SOB and confusion } \\
\text { - HPC: Deteriorated over the } \\
\text { course of } 1 \text { week... } \\
\text { • Performed cardiovascular and } \\
\text { respiratory systems examination } \\
\text { • Viewed her Chest } X \text {-ray and } \\
\text { discussed with Dr West } \\
\text { (Consultant)...... }\end{array}$ & $\begin{array}{l}\text { - Presented patient history } \\
\text { with Dr West and I thought I } \\
\text { covered everything quite well } \\
\text { - Forgotten some steps in heart } \\
\text { auscultation } \\
\text { - Unsure of Antibiotics to } \\
\text { prescribe for HAP }\end{array}$ & $\begin{array}{l}\text { Dr West } \\
\text { • History taken was } \\
\text { comprehensive, good } \\
\text { focus on ICE } \\
\text { • Handover was not well } \\
\text { summarised and I had to } \\
\text { practise as though I was } \\
\text { doing it over the phone }\end{array}$ & $\begin{array}{l}\text { - Read Trust Pneumonia } \\
\text { antibiotics policy } \\
\text { - Practise Chest } \\
\text { Examination } \\
\text { - Take more histories and } \\
\text { present them to seniors } \\
\text { using SBAR model }\end{array}$ & $\begin{array}{l}\text { - Done } \\
\text { 29 Jan } 2015 \\
\text { - Done } \\
3^{\text {rd }} \text { Feb } 2015\end{array}$ \\
\hline $\begin{array}{l}03 \text { Feb } \\
2015\end{array}$ & $\begin{array}{l}\text { Audit Project on Pre-op } \\
\text { medication compliance } \\
\text { - Implemented improvement plan } \\
\text { of briefing nursing staff in pre-op } \\
\text { assessment on Trust Nil-by-Mouth } \\
\text { policy.... } \\
\text { - Presentation was given (slides } \\
\text { uploaded } 3^{\text {rd }} \text { Feb 2015) and } \\
\text { feedback obtained }\end{array}$ & $\begin{array}{l}\text { - Presentation was given in } \\
\text { encouraging tone as I was } \\
\text { trying to rally the nursing } \\
\text { staff's cooperation in } \\
\text { completing the audit cycle } \\
\text { - Could have better prepared } \\
\text { for Question \& Answer }\end{array}$ & $\begin{array}{l}\text { Audience Feedback } \\
\text { forms } \\
\text { - Presentation was easy to } \\
\text { understand and objectives } \\
\text { were clearly laid out } \\
\text { - Nursing staff would like } \\
\text { some kind of handout to } \\
\text { help remember content of } \\
\text { presentation }\end{array}$ & $\begin{array}{l}\text { - Send email to all nursing } \\
\text { staff involved and invite } \\
\text { them to email me any } \\
\text { questions/ difficulties they } \\
\text { face } \\
\text { - Print Trust Policy } \\
\text { summary table in } \\
\text { laminated card and hand } \\
\text { out to nursing.... }\end{array}$ & $\begin{array}{l}\text { Done } \\
\text { 04 Feb } 2015\end{array}$ \\
\hline
\end{tabular}

Note. PC: Presenting complaint; HPC: History of presenting complaint; HAP: Hospital-acquired pneumonia; ICE: Ideas, Concerns, and Expectations; SBAR: Situation, Background, Assessment, and Recommendations

The same concept can also be applied to the use of eportfolios in specialty training applications. Health Education England's website ${ }^{[30]}$ has published several Person Specifications for each specialty, containing e-portfolio requirements that applicants have to demonstrate during application into specialty training, and also forms the basis on which interviewers shape their interview questions. ${ }^{[32]}$

\section{Conclusions}

This article has reviewed some of the key components which ought to be included in e-portfolios, which demonstrates a clinician's competencies for meeting revalidation or training requirements and introduced a simple "Do, Reflect, Plan, Act" framework aims to keep entries succinct, organised and presentable, allowing the e-portfolio to be a good learning tool and help improve medical practice.

Creating and maintaining a huge portfolio containing all our experiences, thoughts and reflections is no simple task, and is often done in addition to the long working hours of medical professionals. To some, this process will be seen as a significant step forward in integrating regulatory and educational approaches to better healthcare, ${ }^{[33]}$ while others might find it a bureaucratic nightmare or merely a "tick-box exercise". ${ }^{34]}$ A profession ought to be self-regulatory, thus the time spent recording evidence of work done, reflecting on it, and devising methods to improve practice ("Do, Reflect, Plan, Act"), should be seen as part of individual professionalism. The annual appraisals and revalidation can then serve as complement to monitor progress and identify areas of practice to improve on, as well as build up achievable milestones in throughout a training curriculum.

\section{Author contributions}

The corresponding author, Joseph Wan is primarily involved in the conception and design of the review project, and drafting of the manuscript. Dr Neil Metcalfe is primarily involved in the literature review and gathering of research articles and guidelines, as well as critically revising and editing of the manuscript draft.

\section{ACKNOWLEDGEMENTS}

The authors express their heartfelt gratitude to Miss Tista Chakravarty-Gannon, GMC Regional Liaison Advisor, for providing invaluable advice on the GMC guidelines, GMC registration and re-validation processes.

\section{CONFLICTS OF INTEREST Disclosure}

The authors declare they have no competing interests. 


\section{REFERENCES}

[1] Vance G, Williamson A, Frearson R, et al. Evaluation of an established learning portfolio. Clin Teach. 2013; 10(1): 21-26. PMid: 23294739. http://dx.doi.org/10.1111/j.1743-498X. 2012 $.00599 . \mathrm{x}$

[2] Lewis KO, Baker RC. The development of an electronic educational portfolio: An outline for medical education professionals. Teaching and learning in medicine. 2007; 19(2): 139-147. PMid: 17564541. http://dx.doi.org/10.1080/10401330701332219

[3] General Medical Council. Good Medical Practice. 2012.

[4] General Medical Council. GMP framework for appraisal and revalidation. 2013

[5] Royal College of General Practitioners. The RCGP Guide to the Revalidation of General Practitioners. 2014.

[6] Royal College of Surgeons England. Revalidation Guide for Surgery. 2014.

[7] Williamson A. Building a portfolio. BMJ Careers. Sep 2011.

[8] Department of Health. A Reference Guide for Postgraduate Specialty Training in the UK (Gold Guide). Fifth edition. May 2014.

[9] Belcher R, Jones A, Smith LJ, et al. Qualitative study of the impact of an authentic electronic portfolio in undergraduate medical education. BMC Med Educ. 2014; 14(1): 265. PMid: 25515320 http://dx.doi.org/10.1186/s12909-014-0265-2

[10] Knight R, Henstridge-Blows J, Stacey H, et al. Reflection: how do I do it? Student BMJ. 2013; 21: 6387.

[11] Gómez SS, Ostos EMC, Solano JMM, et al. An electronic portfolio for quantitative assessment of surgical skills in undergraduate medical education. BMC Med Educ. 2013; 13(1): 65. PMid: 23642100. http://dx.doi.org/10.1186/1472-6920-13-65

[12] General Medical Council. Tomorrow's Doctors. 2009.

[13] Garrett BM, Jackson C. A mobile clinical e-portfolio for nursing and medical students, using wireless personal digital assistants (PDAs). Nurse Educ Today. 2006; 26(8): 647-654. PMid: 17011674 http://dx.doi.org/10.1016/j.nedt.2006.07.020

[14] British Medical Association (BMA) Medical Students Conference 2013. Consistent e-portfolio system could improve career development. BMA News. April 2013.

[15] Postgraduate Medical Education and Training Board. The Annual Review of Competence Progression (ARCP) process - a short review by the Postgraduate Medical Education and Training Board. Jan 2010.

[16] Foundation Programme (United Kingdom). Guide to the ARCP process. 2012

[17] Foundation Programme (United Kingdom). FP Curriculum 2012 updated for 2014.
[18] Intercollegiate Surgical Curriculum Programme (ISCP). The Intercollegiate Surgical Curriculum. Jul 2013.

[19] Joint Royal Colleges of Physicians Training Board. ARCP Decision Aids.

[20] Federation Royal Colleges of Physicians. The Physician of Tomorrow: Curriculum for Core Medical Training and Acute Care Common Stem (Medicine) (Acute Medicine Level One). Federation Royal Colleges of Physicians UK. 2007;103-13.

[21] Joint Royal Colleges of Physicians Training Board. Specialty Training Curriculum for Core Medical Training. August 2013.

[22] Donato AA, Harris I. Use of Portfolios for Assessment of Resident Teaching Skills. Journal of graduate medical education. 2013; 5(3): 476-480. PMid: 24404313. http://dx.doi.org/10.4300/JGM E-D-12-00309.1

[23] Driessen E. Are learning portfolios worth the effort? Yes. British Medical Journal. 2008; 337. PMid: 18621759. http://dx.doi.o $\mathrm{rg} / 10.1136 / \mathrm{bmj}$. 39540.415822. AD

[24] Royal College of Anaesthetists. Supporting Information for Appraisal and Revalidation: Guidance for Doctors in Anaesthesia, Intensive Care and Pain Medicine. 2014.

[25] Academy of Medical Royal Colleges. Specialty Guidance for Appraisal and Revalidation.

[26] Schmitz CC, Whitson BA, Van Heest A, et al. Establishing a usable electronic portfolio for surgical residents: trying to keep it simple. Journal of Surgical Education. 2010; 67(1): 14-18. PMid: 20421084. http://dx.doi.org/10.1016/j.jsurg. 2010.01.001

[27] Tulinius C, Hølge-Hazelton B. Continuing professional development for general practitioners: supporting the development of professionalism. Medical Education. 2010; 44(4): 412-420. PMid: 20444077. http://dx.doi.org/10.1111/j.1365-2923.2010.03620.x

[28] Benjamin A. The Competent Novice: Audit: how to do it in practice. BMJ. 2008; 336.7655:1241.

[29] King A. A trainee's guide to surviving ePortfolio. Clin Med. 2013; 13(4): 367-69. PMid: 23908506. http://dx.doi.org/10.7861 /clinmedicine.13-4-367

[30] National Health System England. Core Surgical Training - CT1. Person Specification 2015.

[31] Health Education England. 2015 Person Specifications. NHS England 2015.

[32] Joint Committee on Surgical Training. CCT Application Guidelines$\mathrm{CV}$ and Consolidation Sheets Submission.

[33] Marshall M. Revalidation: a professional imperative. British Journal of General Practice. 2009; 59(564): 476-477. PMid: 19566993. http://dx.doi.org/10.3399/bjgp09X453486

[34] Macaulay CP, Winyard PJW. Reflection: tick box exercise or learning for all? BMJ Careers November. 2012. 